\title{
Knowledge about and Attitudes of Interdisciplinary Team Members toward Occupational Therapy Practice: Implications and Future Directions
}

\author{
Naser M. Alotaibi ${ }^{a} \quad$ Fahad S. Manee ${ }^{a} \quad$ Lisa J. Murphy ${ }^{b} \quad$ Mehdi Rassafiani $^{a, c}$ \\ a Occupational Therapy Department, Faculty of Allied Health Sciences, Kuwait University, Jabriya, Kuwait; \\ ${ }^{b}$ Department of Occupational Therapy, School of Primary Health Care, Faculty of Medicine, Nursing and Health \\ Sciences, Monash University, Melbourne, VIC, Australia; 'Pediatric Neurorehabilitation Research Center, \\ The University of Social Welfare and Rehabilitation Sciences, Tehran, Iran
}

\section{Significance of the Study}

- In this study, interprofessional team members showed limited knowledge about occupational therapy practice, while their attitudes were promising. To overcome the shortcomings in interprofessional collaboration activities among the interdisciplinary team members, we propose the development of interprofessional initiative committees in the Health Science Center at Kuwait University as well as in the Ministry of Health in Kuwait.

\section{Keywords}

Interprofessional education - Collaborative practice ·

Occupational therapy $\cdot$ Kuwait

\begin{abstract}
Objectives: In Kuwait, knowledge and attitudes of the health care teams toward occupational therapy practice (OTP) have not been investigated. This current study sought to explore the knowledge about and attitudes of interdisciplinary team members toward OTP. Subjects and Methods: This crosssectional study involved developing and validating a tool to serve the purpose of the study. We used a modified Delphi method to develop a tool that assessed occupational therapy (OT) knowledge (OT areas of practice, domains, and phi-
\end{abstract}

losophy) as well as attitudes toward OTP. Descriptive statistics were utilized, and nonparametric tests were used to compare knowledge and attitudes along with the demographic data. Results: A convenience sample of 98 participants from various disciplines participated in this study. The tool was found to have an adequate content validity for a total of 27 items and satisfactory reliability (internal consistency); Cronbach's a-values for the knowledge and attitudes subscales were 0.88 and 0.74 , respectively. The overall knowledge level of OTP among the participants was limited, whereas their attitudes were favorable. Characteristics of being a female $(p=0.01)$, a nurse ( $p=0.02)$, and working experiences $\geq 10$ years $(p=0.01)$ contributed significantly to the knowledge of OTP. The results further indicated that participants working in general hospitals $(p=0.02)$ and working

\begin{tabular}{ll}
\hline KARGER & $\begin{array}{l}\text { @ 2018 The Author(s) } \\
\text { Published by S. Karger AG, Basel }\end{array} \quad \begin{array}{l}\text { Karger } \\
\text { Open access }\end{array}$ \\
E-Mail karger@karger.com & $\begin{array}{l}\text { This is an Open Access article licensed under the Creative Commons } \\
\text { Attribution-NonCommercial-4.0 International License (CC BY-NC) } \\
\text { (http://www.karger.com/Services/OpenAccessLicense), applicable to } \\
\text { the online version of the article only. Usage and distribution for com- } \\
\text { mercial purposes requires written permission. }\end{array}$
\end{tabular}


with occupational therapists $(p<0.001)$ showed significantly better attitudes toward OTP. Conclusion: For effective collaborative practice and better patients' outcomes, the study findings recommend the development of interprofessional initiative committees targeting educational settings as well as clinical environments.

(c) 2018 The Author(s)

Published by S. Karger AG, Basel

\section{Introduction}

Interdisciplinary teamwork requires a high level of collaboration and communication between health care professionals; it has been shown to prevent duplication of services, promote satisfaction among team members, minimize fragmentation of care, reduce health care costs, and to facilitate higher levels of patient satisfaction $[1,2]$. The success of teamwork may require proper communication, shared collaboration, and an understanding of the roles of each discipline within the health care team [1]. An important factor that limits successful interdisciplinary teamwork, however, could relate to the lack of understanding of the specific roles that each profession can contribute to the whole team $[3,4]$. Limited knowledge about the roles of team members can lead to ineffective communication, poor interprofessional relationships, underestimation of the roles of other health professionals, and diminished appreciation of the unique contributions of each discipline $[3,4]$. These factors may consequently reduce the quality of patient care.

One method of facilitating a stronger interdisciplinary teamwork is to clearly define the roles of the team members in each discipline. The World Health Organization developed a framework which indicated that "for health workers to collaborate effectively and improve health outcomes, two or more from different professional backgrounds must first be provided with opportunities to learn about, from and with each other" [5].

An occupational therapist is a vital member of an interdisciplinary team and can bring a unique perspective to patient care. The tenets underpinning occupational therapy $(\mathrm{OT})$ as a health care profession contend that people are occupational beings who need to participate in everyday activities to promote health, maximize function, and achieve self-actualization [6]. However, a lack of awareness of the OT knowledge base among other team members, as well as a lack of understanding about the nature of the occupation and its effect on health and wellbeing are factors that have been found to limit effective interdisciplinary teamwork $[1,7]$.

Knowledge about and Attitudes toward Occupational Therapy
The lack of a clear understanding of the roles of occupational therapists has been evident in some parts of the world. For example, a study conducted in Jordan reported that knowledge about OT was limited among physicians, nurses, and physical therapists. Their perception of the scope of OT and areas of specialty was lacking in practice areas such as emergency care units, schools, private practices, oncology, cardiac rehabilitation, and neonatal units [8]. In addition, another study found that the majority of participants recognized OT as an autonomous health care profession that played a vital role within the rehabilitation team, but mainly identified activities of daily living and hand therapy as the scope of occupational therapy practice (OTP) [9]. Similar issues toward the role confusion of OT were also reported in India [10], South Africa [11], and Iran [12].

In Kuwait, knowledge and attitudes of the health care teams toward OT have not been investigated. Therefore, the current study sought to explore the knowledge about and attitudes of interdisciplinary team members toward OTP, by developing and validating a tool for this purpose. This can contribute to increasing awareness about the role and value of OT within the team and to helping occupational therapists to disseminate knowledge to other health care members and thus supporting collaborative practice.

\section{Methods}

\section{Study Design}

This cross-sectional study utilized a descriptive research design. We developed an instrument to measure the knowledge about and attitudes of interdisciplinary team members concerning the practice of OT. A methodological research design for developing the instrument was also used. The instrument is called Knowledge and Attitudes toward Occupational Therapy Practice (KAOTP).

\section{Participants}

A convenience sample of health professionals and teachers working in the Ministry of Health, Ministry of Education, and private sectors in Kuwait were invited to participate in this study. Inclusion criteria were: (1) school teachers, health care professionals either in educational settings or clinics including physiatrists, psychiatrists, physical therapists, speech-language pathologists, nurses, neurologists, pediatricians, psychologists, and social workers; (2) currently working in government or private sector schools and hospitals; and (3) working with adult or pediatric patients.

\section{Development and Validation of the KAOTP}

An extensive search was conducted using relevant databases such as SCOPUS and MEDLINE to identify and generate items for the instrument. The "Occupational Therapy Practice Framework: 
Table 1. Occupational therapy knowledge items $(n=98)$

\begin{tabular}{|c|c|c|}
\hline & $\begin{array}{l}\text { Correct, } \\
n(\%)\end{array}$ & $\begin{array}{l}\text { Wrong, } \\
n(\%)\end{array}$ \\
\hline \multicolumn{3}{|l|}{ Occupational therapy areas of practice (specializations) } \\
\hline Orthopedics & $45(45.9)$ & $53(54.1)$ \\
\hline Cardiopulmonary rehabilitation & $19(19.4)$ & $79(80.6)$ \\
\hline Neonatal care & $12(12.2)$ & $86(87.8)$ \\
\hline Geriatrics/elderly care & $38(38.8)$ & $60(61.2)$ \\
\hline Burn rehabilitation & $25(29.6)$ & $69(70.4)^{1}$ \\
\hline Cognitive rehabilitation & $37(37.8)$ & $61(62.2)$ \\
\hline Oncology & $13(13.3)$ & $85(86.7)$ \\
\hline Rheumatology & $20(20.4)$ & $78(79.6)$ \\
\hline Child health (pediatrics) & $39(39.8)$ & $59(60.2)$ \\
\hline Palliative care & $25(25.5)$ & $73(74.5)$ \\
\hline School-based system & $40(40.8)$ & $58(59.2)$ \\
\hline Driving rehabilitation & $18(18.4)$ & $80(81.6)$ \\
\hline Mental health (psychiatric rehabilitation) & $42(42.9)$ & $56(57.1)$ \\
\hline Ergonomics & $16(16.3)$ & $82(83.7)$ \\
\hline \multicolumn{3}{|l|}{ Domains of occupational therapy } \\
\hline Activities of daily living & $71(72.4)$ & $27(27.6)$ \\
\hline Education & $38(38.8)$ & $60(61.2)$ \\
\hline Work & $40(40.8)$ & $58(59.2)$ \\
\hline Social participation & $39(39.8)$ & $59(60.2)$ \\
\hline Leisure & $11(11.2)$ & $87(88.8)$ \\
\hline Rest and sleep & $15(15.3)$ & $83(84.7)$ \\
\hline Play & $27(27.6)$ & $71(72.4)$ \\
\hline \multicolumn{3}{|l|}{ Philosophy of occupational therapy } \\
\hline \multirow{3}{*}{$\begin{array}{l}\text { The most important reason patients are referred to occupational therapy } \\
\text { relates to the difficulty to participate in valued occupations/roles } \\
\text { A set of beliefs that any occupational therapist must use while working with } \\
\text { patients is known as philosophy of occupational therapy } \\
\text { An important belief in the philosophy of occupational therapist is to provide } \\
\text { opportunities for the patient }\end{array}$} & $60(62.5)$ & $36(37.5)^{1}$ \\
\hline & $43(44.8)$ & $53(55.2)^{1}$ \\
\hline & $50(53.2)$ & $44(46.8)^{1}$ \\
\hline
\end{tabular}

The italicized response in each question is considered the right choice for that question. ${ }^{1}$ Numbers may not add up to the total due to missing responses.

Domain and Process" [6] also guided the general knowledge questions. An initial pool of 48 items was generated to address practice areas, domains of practice, and underpinning tenets of OT. An expert panel from the OT discipline was formed in order to establish the content validity of the instrument. The panel consisted of three academic faculty members and three clinicians of various nationalities, professional experiences, backgrounds, and theoretical underpinnings in OTP. The mean for clinical experience was 12.7 years $(\mathrm{SD}=6.6)$ and for teaching experience 12.2 years $(\mathrm{SD}=$ 9.5). The panel decided to include questions related to the core of OTP and not to include in-depth items related to the skills and techniques of the discipline. A decision was also made that the instrument would be self-administered. The panel used a modified Delphi method in which the experts worked toward an agreement by conducting a series of discussions in order to ensure the relevance and appropriateness of each item. The discussions considered the feedback from the experts participating in the discussion. The related feedback was then discussed further during each sub- sequent meeting until an agreement is reached. By using the content retention approach, the panel finally retained 27 items, in addition to the 8 demographic items, which formed the final version of the KAOTP.

\section{The Structure and Scoring of the KAOTP}

The final version of the KAOTP consisted of two sections: (1) demographics including participant's age, gender, profession, educational level, work setting, working experience, years of work experience with an occupational therapist, and prior attendance at any OT seminars or workshops; and (2) knowledge and attitudes toward OTP consisting of 27 items divided into two subscales (i.e., knowledge and attitudes).

\section{Knowledge Subscale}

The knowledge subscale has three clusters of items. The first cluster (14 items) consists of the specific OT areas of OTP. The second cluster (7 items) focuses on the domains of OTP, and the 
third cluster (3 items) refers to the general understanding about the philosophy of OT.

The first and second clusters included items from which the participant was instructed to choose all the one(s) that apply. In other words, the chosen responses were considered correct whereas the ones not chosen were considered wrong responses. All 14 items in the first cluster represented current areas of practice, and all 7 items in the second cluster represented current domains of practice. The third cluster (philosophical underpinnings: 3 items) used a multiple-choice format with four answers for each item, and participants were instructed to select the one right answer (Table 1). The total score for the knowledge subscale ranges from 0 to 24 . A higher score indicates a greater knowledge base about OTP.

\section{Attitudes Subscale}

The attitudes subscale consisted of 3 items, targeting the participant's attitudes toward OTP. The items focused on (1) perception of the importance of OT, (2) value of the role of OT in the health care team, and (3) whether they would suggest referring patients in the future to receive OT services. Scoring for each item consisted of a 5-point Likert scale ranging from 1 (strongly disagree) to 5 (strongly agree). The total score on the attitudes subscale ranges from 3 to 15 with a higher score indicating more positive attitudes toward OTP.

Pilot Testing, Reliability, and Internal Consistency of the KAOTP The KAOTP was pilot-tested by 20 health care professionals. Overall, there were no major issues with the administration of the KAOTP in terms of clarity, relevance, or comprehension. During the pilot-testing process, 8 participants expressed some difficulty with wordings of some items in the instrument, which was addressed by revising these items accordingly. The KAOTP was finalized, and the time required for administering the instrument was about $10 \mathrm{~min}$. The KAOTP total scale demonstrated Pearson item total correlations ranging from 0.10 to 0.58 suggesting some items contributed more to the construct of OTP, as was expected with new tools. Cronbach's a-values for the knowledge and attitudes subscales were 0.88 and 0.74 , respectively, indicating a lack of redundancy in the items, and the overall Cronbach's $\alpha$-value of 0.86 indicates a good internal consistency.

\section{Procedures}

The research study was approved by the Institutional Review Board of the Health Science Center at Kuwait University. A formal letter of invitation was mailed to administrators and heads of departments of several schools and hospitals in Kuwait requesting them to inform their target employees (health care professionals and school teachers) about the study. The letter included the purpose of the study, informed consent, and the venue and time of the study. A copy of the KAOTP was also e-mailed to all the departments of the designated professions. An e-mail reminder was sent to all departments weekly before the start of data collection for a period of 1 month to improve participation.

Administration of the KAOTP took place at the Health Sciences Center of Kuwait University. The rationale for the study was explained, and informed consent was obtained. Confidentiality about the data collected and of the study findings was guaranteed to all participants. Participants were asked to answer all KAOTP items to the best of their knowledge in order to ensure complete responses.

Knowledge about and Attitudes toward Occupational Therapy
Table 2. Demographics of the study participants $(n=98)$

\begin{tabular}{|c|c|}
\hline Demographics & $n(\%)$ \\
\hline \multicolumn{2}{|l|}{ Gender } \\
\hline Male & $33(33.7)$ \\
\hline Female & $65(66.3)$ \\
\hline \multicolumn{2}{|l|}{ Age } \\
\hline$<30$ years & $36(38.3)$ \\
\hline 30-39 years & $36(38.3)$ \\
\hline$\geq 40$ years & $22(23.4)$ \\
\hline Mean \pm SD & $33.9 \pm 9.2$ \\
\hline \multicolumn{2}{|l|}{ Level of education } \\
\hline Diploma & $8(8.3)$ \\
\hline Bachelor & $72(75.0)$ \\
\hline Masters and above & $16(16.7)$ \\
\hline \multicolumn{2}{|l|}{ Profession } \\
\hline Doctors and allied health professionals & $22(22.7)$ \\
\hline Nurses & $50(51.5)$ \\
\hline Teachers & $11(11.3)$ \\
\hline Others & $14(14.4)$ \\
\hline \multicolumn{2}{|l|}{ Work settings } \\
\hline General hospital & $30(31.6)$ \\
\hline Specialized hospital & $25(26.3)$ \\
\hline College/university & $18(18.9)$ \\
\hline Others & $22(23.2)$ \\
\hline \multicolumn{2}{|l|}{ Working experience } \\
\hline$<5$ years & $16(16.8)$ \\
\hline $5-10$ years & $43(45.3)$ \\
\hline $11-15$ years & $17(17.9)$ \\
\hline $16-20$ years & $9(9.5)$ \\
\hline$>20$ years & $10(10.5)$ \\
\hline \multicolumn{2}{|l|}{ Working with OT } \\
\hline Never & $55(57.3)$ \\
\hline$<1$ year & $16(16.7)$ \\
\hline $1-5$ years & $7(7.3)$ \\
\hline $6-10$ years & $12(12.5)$ \\
\hline$>10$ years & $6(6.3)$ \\
\hline \multicolumn{2}{|l|}{ Attended seminars/workshops related to OT } \\
\hline No & $68(71.6)$ \\
\hline Yes & $27(28.4)$ \\
\hline
\end{tabular}

OT, occupational therapy. Numbers may not add up to the total due to missing responses.

\section{Statistical Analyses}

Descriptive statistics were reported for demographics and KAOTP items. The internal consistency and item-total correlations were analyzed using Cronbach's a and Pearson's correlation coefficients, respectively, for the reliability analyses. Nonparametric tests were used to compare knowledge and attitudes along with the demographic data: age, gender, profession, educational level, work setting, working experience, years of work experience with an occupational therapist, and prior attendance at any OT seminars or workshops. Specifically, to examine the associations between demographic data and knowledge and attitudes of the study participants, Mann-Whitney and Kruskal-Wallis ANOVA tests 
Table 3. Descriptive statistics for knowledge about and attitudes scores toward occupational therapy (OT) $(n=$ 98)

Mean \pm SD Median (range)

Knowledge

Knowledge score about areas of OT $(0-14)$

Knowledge score about domains of OT (0-7)

$2(0-14)$

Knowledge score regarding philosophy of OT (0-3)

$2.6 \pm 1.3$

$2(0-6)$

Total knowledge score $(0-24)$

$1.6 \pm 1.0$

$2(0-3)$

$8.2 \pm 4.9$

$6.5(1-21)$

Attitudes

I believe OT is an equally important health care profession as other health care

profession related to the rehabilitation of patients (score 1-5)

I value the role of OT in the rehabilitation of patients (score 1-5)

$4.4 \pm 0.6$

$4.4 \pm 0.7$

$4(3-5)$

I suggest referring patients to receive OT services (score 1-5)

$4.2 \pm 0.7$

$4(1-5)$

Total attitudes score (score 3-15)

$13.0 \pm 1.5$

$4(3-5)$

$13(9-15)$

were used to compare between two independent categories and between more than two independent categories, respectively. $p$ values $<0.05$ (2-tailed) were considered significant. Statistical analyses were performed with SPSS (version 21.0) for Windows (SPSS Inc., Chicago, IL, USA).

\section{Results}

The total sample consisted of 98 participants from various disciplines. There were more women $(n=65,66.3 \%)$ than men $(n=33,33.7 \%)$, and the average age was 33.9 years $(S D=9.2)$. Participants had a wide range of clinical experiences and came from various work settings. More than half of the study participants had no prior work experience with occupational therapists (Table 2).

The mean $( \pm \mathrm{SD})$ knowledge scores of the OT areas of practice (0-14), domains (0-7), and philosophy (0-3) were $4.0 \pm 3.6,2.6 \pm 1.3$, and $1.6 \pm 1.0$, respectively. On the other hand, the mean $( \pm S D)$ of the attitudes scores of the importance of OT profession (1-5), valuing the role of OT (1-5), and recommending referrals to OT services (1-5) were $4.4 \pm 0.6,4.4 \pm 0.7$, and $4.2 \pm 0.7$, respectively. This suggests that the overall knowledge level concerning OT among the participants was limited, whereas the attitudes toward OT were favorable (Table 3).

For the specializations of OTP, the ones identified most frequently by the participants were orthopedics ( $n=45,45 \%)$, mental health $(n=42,42 \%)$, school-based system ( $n=40,40.8 \%)$, and child health $(n=39,39.8 \%)$ whereas the least frequent specializations were neonatal $(n=12,12.2 \%)$ and oncology $(n=13,13.3 \%)$. The domains of OT, activities of daily living $(n=71,72.4 \%)$, work ( $n=58,59.2 \%)$, social participation $(n=39,39.8 \%)$, and education $(n=38,38.8 \%)$ were the most known by the study participants. In contrast, the least known domains were leisure $(n=11,11.2 \%)$, rest and sleep $(n=15$, $15.3 \%)$, and play $(n=27,27.6 \%)$. A majority of the participants selected the correct alternative responses for the overall knowledge items pertaining to OT philosophy (Table 1).

When studying the factors associated with greater knowledge about OTP, being a female $(p=0.01)$, professional status as nurses $(p=0.02)$, and working experiences $\geq 10$ years $(p=0.01)$ significantly contributed to being more knowledgeable about OT than other participants' characteristics. On the other hand, participants working in general hospitals $(p=0.02)$ as well as working with occupational therapists $(p<0.001)$ showed significantly better attitudes toward OTP (Table 4 ).

\section{Discussion}

This study sought to identify the knowledge base and attitudes of potential interprofessional team members toward OTP. The knowledge about OT was limited among the study participants, which has also been reported in the literature from other parts of the world [8-12]. In this study, the participants demonstrated better understanding of the OT philosophy compared with the practice areas and OT domains. Hence, the philosophical underpinnings of OT are perceived as an important element for facilitating interprofessional collaboration [7, 13]. Our study findings, however, suggest that having knowledge about the OT philosophy alone is not sufficient for grasp- 
Table 4. Total knowledge and attitudes scores according to the characteristics of the participants

\begin{tabular}{|c|c|c|c|c|c|}
\hline \multirow[t]{2}{*}{ Characteristics } & \multirow[t]{2}{*}{$n$} & \multicolumn{2}{|c|}{ Knowledge (ranges 0-24) } & \multicolumn{2}{|c|}{ Attitudes (ranges 3-15) } \\
\hline & & median (IQR) & $p$ value & median (IQR) & $p$ value \\
\hline \multicolumn{6}{|l|}{ Gender } \\
\hline Male & 33 & $3(4-9)$ & \multirow[t]{2}{*}{$0.010^{\mathrm{a}}$} & $13(12-15)$ & \multirow[t]{2}{*}{$0.477^{\mathrm{a}}$} \\
\hline Female & 65 & $10(5-13)$ & & $13(12-14)$ & \\
\hline \multicolumn{6}{|l|}{ Age } \\
\hline$<30$ years & 36 & $6(4-10)$ & \multirow[t]{3}{*}{$0.198^{\mathrm{b}}$} & $13(12-14)$ & \multirow[t]{3}{*}{$0.243^{\mathrm{b}}$} \\
\hline 30-39 years & 36 & $6(4-12)$ & & $13(12-14)$ & \\
\hline$\geq 40$ years & 22 & $10(5-15)$ & & $14(12-15)$ & \\
\hline \multicolumn{6}{|l|}{ Level of education } \\
\hline Bachelor/diploma & 80 & $6(4-11)$ & \multirow[t]{2}{*}{$0.194^{\mathrm{a}}$} & $13(12-14)$ & \multirow[t]{2}{*}{$0.173^{\mathrm{a}}$} \\
\hline Masters and above & 16 & $11(5-15)$ & & $14(12-15)$ & \\
\hline \multicolumn{6}{|l|}{ Profession } \\
\hline Doctors and allied health professionals & 22 & $7(4-11)$ & \multirow[t]{4}{*}{$0.022^{\mathrm{b}}$} & $14(12-15)$ & \multirow[t]{4}{*}{$0.077^{\mathrm{b}}$} \\
\hline Nurses & 50 & $9(5-14)$ & & $12(12-14)$ & \\
\hline Teachers & 11 & $6(3-13)$ & & $14(13-15)$ & \\
\hline Others & 14 & $5(3-8)$ & & $13(12-14)$ & \\
\hline \multicolumn{6}{|l|}{ Work settings } \\
\hline General hospital & 30 & $9(4-11)$ & \multirow[t]{4}{*}{$0.168^{\mathrm{b}}$} & $14(12-15)$ & \multirow[t]{4}{*}{$0.019^{\mathrm{b}}$} \\
\hline Specialized hospital & 25 & $10(5-13)$ & & $12(12-13)$ & \\
\hline College/university & 18 & $5(5-10)$ & & $12(12-14)$ & \\
\hline Others & 22 & $6(3-10)$ & & $14(13-14)$ & \\
\hline \multicolumn{6}{|l|}{ Working experience } \\
\hline$<10$ years & 59 & $5(4-11)$ & \multirow[t]{2}{*}{$0.014^{\mathrm{a}}$} & $13(12-14)$ & \multirow[t]{2}{*}{$0.675^{\mathrm{a}}$} \\
\hline$\geq 10$ years & 36 & $10(5-15)$ & & $13(12-15)$ & \\
\hline \multicolumn{6}{|l|}{ Working with OT } \\
\hline No & 55 & $6(4-12)$ & \multirow[t]{2}{*}{$0.515^{\mathrm{a}}$} & $12(12-14)$ & \multirow[t]{2}{*}{$<0.001^{\mathrm{a}}$} \\
\hline Yes & 41 & $8(5-11)$ & & $14(12-15)$ & \\
\hline \multicolumn{6}{|l|}{ Attended seminars/workshops related to OT } \\
\hline No & 68 & $8(5-13)$ & \multirow[t]{2}{*}{$0.182^{\mathrm{a}}$} & $13(12-14)$ & \multirow[t]{2}{*}{$0.441^{\mathrm{a}}$} \\
\hline Yes & 27 & $6(4-10)$ & & $13(12-15)$ & \\
\hline
\end{tabular}

IQR, interquartile range; OT, occupational therapy. ${ }^{a}$ Mann-Whitney test to compare between two independent categories. ${ }^{\mathrm{b}}$ Kruskal-Wallis ANOVA test to compare between more than two independent categories.

ing an adequate understanding of the role of OT. In other words, adequate understanding of the OT philosophy should also be combined with understanding of the areas of practice as well as domains of OT in order to better optimize desired interprofessional collaboration. To illustrate, even though $42 \%$ of the study participants recognized the mental health area as a specialization within OTP, leisure activity, which is an important domain of the mental health area in OTP $[14,15]$ was the least recognized domain by the study participants $(n=11,11.2 \%)$. Occupational therapists thus have a responsibility to establish a wider communication channel with other health care professionals to clearly define their contributions and explain their specific roles in relevant areas of practice [9]. Such education and communication may gener- ate more desired referrals, facilitate interprofessional collaboration and possibly support patients' therapeutic outcomes.

Based on our findings, being a nurse was an important indicator that significantly contributed to grasping a higher level of knowledge about OTP. Similarly, participants with increased working experience ( $\geq 10$ years) also demonstrated greater knowledge about OTP. On the contrary, working with occupational therapists did not contribute to higher knowledge acquisition about OTP. This raises a concern about the reasons behind the lack of knowledge about OTP despite working with occupational therapists. With respect to nurses having more knowledge about OTP, this could be attributed to their professional education curriculum in which more focus about 
OTP was provided. On the other hand, limited knowledge of the participants about OTP despite working with them could be explained by two reasons. First, occupational therapists in Kuwait might not be proactive enough to explain their role and contributions to other team members. Second, the busy clinical environment and possibly the increased patients' loads assigned to occupational therapists may contribute to limited interaction with other health care professionals. In order to understand the rationale behind the lack of knowledge about OTP, a further qualitative study (i.e., a focus group) is of priority. For example, such a qualitative study can accurately answer the question of why being a nurse as well as increased years of working experience contributed significantly to greater knowledge about OTP than working with occupational therapists. Although health care professionals working with occupational therapists did not achieve more knowledge about OTP, they showed significantly better attitudes toward OTP. This could be attributed to the desired therapeutic outcomes observed from the provision of OT services to different patient populations. Occupational therapists are therefore encouraged to leverage such appreciation by expanding the knowledge of OT among team members.

The attitudes of participants toward OTP were generally favorable, supporting OT as an independent and autonomous health care profession. This finding concurs with the positive attitudes reported among health care professionals in Jordan by AlHeresh and Nikopoulos [9], where a specific feature of the study was the perception of OT as a vital health care profession that plays a key role within the interprofessional rehabilitation process. In addition, the results in our study indicated that the participants were in favor of referring patients to receive OT services. This implies that the participants recognize occupational therapists as valuable members of the rehabilitation team.

The results of this study revealed that attending workshops related to OTP did not significantly contribute to increased knowledge of OT. Such a finding was not congruent with the published literature indicating that attending educational workshops given by occupational therapists, or about OT, was significantly associated with an increased knowledge base and understanding of OTP $[16,17]$. This could be explained by two main reasons. First, the small sample size $(n=27)$, who reported attending OT, could have influenced this finding. Second, the nature of the workshops was not explained as it could be so general in which the participants did not have a full understanding of the role and scope of OTP. Therefore, future studies on OT workshops are needed to specify the extent and nature of the workshop as broad or specific. Questionnaires should also ascertain whether these workshops are delivered by occupational therapists or other health care professionals who might generally mention the contributions of OT as part of the rehabilitation team.

Further studies are recommended to overcome the issue of role confusion and ambiguity among related health care professions, particularly in Kuwait where there are only limited research studies in the area of interprofessional education (IPE) [18]. Therefore, as suggested by Alotaibi et al. [18], it is vital that the Kuwait University incorporates changes within the curricula of its various health-related departments to improve the understanding of knowledge bases and values of these professions. The addition of IPE courses within the health care curricula was also perceived as crucial element internationally $[9,19-22]$. It is important, however, to note that the application of IPE in the health care curricula requires practical and structured learning experiences of learning about, from and with other health care students [21,23]. Doing so can guarantee a better use of IPE within different educational institutions as opposed to merely conducting educational seminars or tutorial sessions [24].

To illustrate the usefulness of applying true IPE within the educational curricula, involving the students in practical learning experiences or community-based projects demonstrated favorable learning outcomes of IPE experiences for students of various health care professions [23]. Hence, OT, physical therapy, and pharmacy students participated in a screening project of risk of fall in elderly patients living in the community. The students of each profession applied their unique role with these patients including environmental screening (OT students), gait and balance screening (physical therapy students), and medication reviews (pharmacy students). Through using validated measures such as the Readiness for Interprofessional Learning Scale and the Interdisciplinary Education Perception Scale, the study findings demonstrated positive perception of the students with relevance to team working, communication, and patient care. The students also reported that such learned activity is practical and reflective of their future practice [23]. Therefore, we suggest the inclusion of both cross-sectional as well as longitudinal research studies to document and monitor the effectiveness of IPE activities within these educational curricula using validated tools and outcome measures.

Additionally, as a prerequisite to the success of such IPE curricula and to ensure effective collaborative practice among students as well as future health care profes- 
sionals, they ought to have a clear representation and understanding of their own professional knowledge and values during their interprofessional team functioning [19, $21,22]$. For example, as occupational therapists and physical therapists work closely with each other in various practice settings [25], their professional knowledge and values are not always clear to one another which could result in conflict related to service provision and therefore influence the success of interprofessional collaboration [19]. As a result, both professionals are encouraged to strive to make their knowledge and values explicit to each other to support interprofessional competence and enable interprofessional collaboration.

Given the study findings, we propose the development of interprofessional initiative committees not only in $\mathrm{Ku}$ wait University, but also within the Ministry of Health in Kuwait to address and support research and issues targeting IPE and collaborative practice. The main outcomes of these initiatives are geared toward improving IPE learning strategies, assessing the effectiveness of various approaches and integrating the values of IPE toward the improvement of practice [26]. To ensure global service delivery, it is noteworthy to indicate that policy-makers and health leaders in the Ministry of Health are encouraged to support the application of such initiatives to be addressed not only in rehabilitation clinics but also within the primary health care and public health settings [27].

In addition, future studies should validate existing tools, such as the practice site readiness for IPE, to assess and monitor IPE initiatives thus supporting interprofessional collaborations among various interdisciplinary team members [28]. Hence, using pre- and post-test research design, prospective, longitudinal, and experimental studies can serve as valuable methods to document and measure the outcomes of various IPE techniques and strategies in Kuwait. Finally, it is imperative that additional research is needed to conduct qualitative studies such as focus groups with various interdisciplinary team members to better understand facilitators and barriers to effective interprofessional collaboration with other team members. This may also assist in identifying strategies and plans to improve future interprofessional care of different patient populations.

The main limitation of this study was the use of nonprobability sampling (convenience sample) which limits the generalizability of the study findings. Hence, due to the lack of available databases for all doctors/therapists of the designated professions, only e-mails were sent to their departments for circulation. Therefore, it is recommended that the Ministry of Health supports the development of databases for all registered doctors/therapists, thus contributing to future engagements in various researchrelated activities [29]. An additional limitation was having all right answers in clusters 1 and 2 to choose from which may have contributed to bias of the study results. Adding wrong answers, such as branches and domains related to other health professions, would have provided an in-depth analysis and interpretations thus enriching the findings of the study. Another limitation could be that the KAOTP instrument does not address the skills and values of OTP, which could be a limiting factor in gaining a holistic picture of OTP. Future studies, therefore, are suggested to enquire about the participants' knowledge related to OT treatment techniques and strategies within the clinical environment. Moreover, more attitudes items would have provided broader perspectives about the participants' attitudes toward OTP.

\section{Conclusion}

This study showed that interprofessional team members had limited knowledge about OTP, while their attitudes toward OTP were promising. The development of interprofessional initiative committees in Kuwait to support interprofessional collaboration is a priority. The adoption of the contingency approach in the clinical environment is also needed with a particular emphasis on clarifying roles and goals of each health care discipline with the other interrelated health care professionals and team members [30]. This study contributes to the academic and research work in the important area of IPE and collaborative practice, thus improving patients' outcomes in Kuwait.

\section{Acknowledgments}

This study was supported by a grant from Kuwait University (NO02/13).

We appreciate the guidance provided by Prof. Paul Russel at Christian Medical College, India. We extend our appreciation to Dr. Mohammed S. Nadar, at the Occupational Therapy Department, Kuwait University, for his inputs and contribution to improve this paper.

\section{Disclosure Statement}

The authors report no conflicts of interest. 


\section{References}

1 White MJ, Gutierrez A, McLaughlin C, Eziakonwa C, Newman LS, White M, et al. A pilot for understanding interdisciplinary teams in rehabilitation practice. Rehabil Nurs. 2013 May-Jun;38(3):142-52.

2 O'Leary KJ, Sehgal NL, Terrell G, Williams MV; High Performance Teams and the Hospital of the Future Project Team. Interdisciplinary teamwork in hospitals: a review and practical recommendations for improvement. J Hosp Med. 2012 Jan;7(1):48-54.

3 Sargeant J, Loney E, Murphy G. Effective interprofessional teams: "contact is not enough" to build a team. J Contin Educ Health Prof. 2008;28(4):228-34.

4 Peabody MA, Demanchick SP. Interprofessional opportunities: understanding roles incollaborative practice. Int J Play Ther. 2016; 25(2):102-11.

5 Gilbert JH, Yan J, Hoffman SJ. A WHO report: framework for action on interprofessional education and collaborative practice. J Allied Health. 2010;39 Suppl 1:196-7.

6 American Occupational Therapy Association. Occupational therapy practice framework: domain and process (3rd edition). Am J Occup Ther 2014;68:S1-S48.

7 Fossey E. Effective interdisciplinary teamwork: an occupational therapy perspective. Australas Psychiatry. 2001;9(3):232-4.

8 Tariah HS, Abulfeilat K, Khawaldeh A. Health professionals' knowledge of occupational therapy in jordan. Occup Ther Health Care. 2012 Jan;26(1):74-87.

9 AlHeresh R, Nikopoulos CK. The role of the occupational therapist in Jordan: a survey of the members of the healthcare team exploring their knowledge about occupational therapy in rehabilitation hospitals. Disabil Rehabil. 2011;33(9):778-86.

10 Guru R, Siddiqui MA, Ur-Rehman A. Professional identity (role blurring) of occupational therapy in community mental health in India. Isr Med J. 2013;5:155-9.
11 Naidoo D, Van Wyk J, Joubert RW. Exploring the occupational therapist's role in primary health care: listening to voices of stakeholders. Afr J Prim Health Care Fam Med. 2016 Aug; 8(1):e1-9.

12 Shafaroodi N, Kamali M, Parvizy S, Mehraban AH, O'Toole G. Factors affecting clinical reasoning of occupational therapists: a qualitative study. Med J Islam Repub Iran. 2014 Feb;28:8.

13 Turner A. The Elizabeth Casson Memorial Lecture 2011: occupational therapy - a profession in adolescence? Br J Occup Ther. 2011; 74(7):314-22

14 Lipskaya-Velikovsky L, Avrech Bar M, Bart O. Context and psychosocial intervention in mental health. Scand J Occup Ther. 2014 Mar; 21(2):136-44

15 Wasmuth S, Pritchard K, Kaneshiro K. Occupation-based intervention for addictive disorders: a systematic review. J Subst Abuse Treat. 2016;62:1-9.16.

16 Doyle SD, Bennett S. Feasibility and effect of a professional education workshop for occupational therapists' management of upperlimb poststroke sensory impairment. Am J Occup Ther. 2014 May-Jun;68(3):e74-83.

17 Hui C, Snider L, Couture M. Self-regulation workshop and Occupational Performance Coaching with teachers: A pilot study. Can J Occup Ther. 2016 Apr;83(2):115-25.

18 Alotaibi N, Shayea A, Nadar M, Abu Tariah H. Investigation into health science students' awareness of occupational therapy: implications for interprofessional education. J Allied Health. 2015;44(1):3-9.

19 Aguilar A, Stupans I, Scutter S, King S. Exploring how Australian occupational therapists and physiotherapists understand each other's professional values: implications for interprofessional education and practice. J Interprof Care. 2014 Jan;28(1):15-22.
20 Bondoc S, Wall T. Interprofessional educational experience to assist in student readiness toward neurorehabilitation. Occup Ther Health Care. 2015 Apr;29(2):153-64.

21 Brewer ML, Rosenwax L. Can interprofessional practice solve the vexing question of 'What is occupational therapy'? Aust Occup Ther J. 2016 Aug;63(4):221-2.

22 Hudson CC, Gauvin S, Tabanfar R, Poffenroth AM, Lee JS, O'Riordan AL. Promotion of role clarification in the Health Care Team Challenge. J Interprof Care. 2017 May;31(3): 401-3.

23 Kurowski-Burt AL, Evans KW, Baugh GM, Utzman RR. A community-based interprofessional education fall prevention project. J Interprof Educ Pract. 2017;8:1-5.

24 Davidson M, Smith RA, Dodd KJ, Smith JS, O'Loughlan MJ. Interprofessional pre-qualification clinical education: a systematic review. Aust Health Rev. 2008 Feb;32(1):11120.

25 Higgs J, Refshauge K, Ellis E. Portrait of the physiotherapy profession. J Interprof Care. 2001 Feb;15(1):79-89.

26 Schmitt MH, Gilbert JH, Brandt BF, Weinstein RS. The coming of age for interprofessional education and practice. Am J Med. 2013 Apr;126(4):284-8.

27 White F. Primary health care and public health: foundations of universal health systems. Med Princ Pract. 2015;24(2):103-16.

28 Zorek JA, Blaszczyk AT, Haase MR, Raehl CL. Practice Site Readiness for Interprofessional Education (PRIPE): instrument development and pilot study. Curr Pharm Teach Learn. 2014;6(1):32-40.

29 Aljadi SH, Alrowayeh HN, Alotaibi NM, Taaqi MM, Alquraini H, Alshatti TA. Research amongst physical therapists in the state of $\mathrm{Ku}$ wait: participation, perception, attitude and barriers. Med Princ Pract. 2013;22(6):561-6.

30 Reeves S, Lewin S, Espin S, et al. International teamwork for health and social care. Oxford: Blackwell-Wiley; 2010. 